\title{
Cultural contextualisation of learning with the World Wide Web
}

\author{
M. Wild \\ School of Management Information Systems, Edith Cowan \\ University, Pearson Street, Churchlands, \\ Western Australia 6018. \\ e-mail:m.wild@cowan.edu.au

\section{Henderson} \\ School of Education, James Cook University, Townsville, \\ Australia 4811. \\ e-mail: lynette.henderson@jcu.edu.au
}

\begin{abstract}
There is a developing urgency about how Australian universities should make use of the World Wide Web to best meet the needs of culturally diverse students, especially those of Asian origin. This urgency is the result of both global and internal pressures, some political, (consider the imminence of the 'Hanson movement' against a multicultural Australial) some technical, some social. To miss the current opportunity to exploit Web technologies to design, implement and market effective instructional courses will be to hand over a potentially billion dollar market to overseas competitors, especially those of the United Kingdom and the United States. One of the most pressing problems in this context is how to provide instructional materials in a model of teaching and learning that is cost effective, makes extensive use of Web technologies to provide for flexibility in learning, and that is culturally appropriate. This paper outlines an approach and model for investigating and developing culturally appropriate instructional materials.
\end{abstract}

1 P. Kelly (1997). The challenge of Pauline Hanson. Focus: The Weekend Australian, 26-27 April, 1997, pp 21-22. In this article, Paul Kelly outlines the urgent need for all Australians, to address the 'racial isolationism' and antimulticultural sentiments propagated in Hanson's One Nation Party, and in its manifesto: Pauline Hanson: The Truth. 
The following hypotheses are central to our work:

- Existing cultural influences in instructional materials designed and delivered on the World Wide Web by (Australian) universities, and intended for use by culturally diverse students, are minimal and ineffective.

- The efficacy of learning based in the use of the World Wide Web for instructional purposes can be improved by the adoption of a culturally appropriate model of instructional design.

- Culture is a significant factor in determining the effectiveness of learning materials created in the World Wide Web and intended for use by culturally diverse students.

In testing these hypotheses, we intend to provide the empirical research to help determine the most appropriate ways of using the Web to stimulate effective learning at tertiary level for all learners, whatever their cultural heritage or perspectives.

\section{Keywords}

Distributed learning systems, WWW, Multi-cultural tertiary education, Multimedia instructional design, Flexible learning

\section{INTRODUCTION}

In the age of cyberspace education, interactive learning and globalisation of the learning process ... universities webbed together by electronics and learning systems based upon new academic paradigms will not be easily denied in the twenty-first century.' (Pelton, 1996 20)

Here Pelton gives an insight into the imperatives presented by widespread usage of new communication technologies. Tertiary education will necessarily assume a new shape in a communications rich world, and be driven by developing customers' demands for greater sophistication, flexibility and cultural appropriateness in learning systems. In particular, universities are increasingly targeting culturally diverse students and will need to develop culturally contextualised applications of these new technologies.

The Internet and especially the World Wide Web is increasingly being used as a vehicle for flexible learning, where learning is seen to be free from geographical, time and participation restraints (Nguyen, Tan, and Kezunovic, 1996; Rossman, 1992). Numerous tertiary institutions are rapidly investing considerable resources and faith in the Web as a means of conveying both the administrative and the pedagogical materials for student learning. Australia figures prominently amongst the nations of the world which use distributed information systems, such as the Web, to deliver education (Paulsen, 1992; Rudra, 1994). Too often however, paper based information resources are simply being converted into 'electronic pageturning' materials for accessing via the Web. There is little regard for appropriate pedagogic design models and strategies for exploiting the Web as an instructional 
medium (Alexander, 1995; Reeves, 1996; Wild, 1996b), particularly for students originating and studying with different cultural perspectives.

Distributed learning systems on the Web have the potential and often the intention of reaching greater numbers of culturally diverse students. The key to success in the use of the Web across cultural boundaries lies in the appropriate pedagogic design of on line educational environments (Harasim, 1995; Henderson, 1996). Our own recent research (Henderson, Patching, and Putt, 1996; Oliver, 1996; Oliver, Herrington, and Omari, 1996; Wild, 1996a; Wild, 1996b; Wild and Omari, 1996) has demonstrated that the Web is almost always chosen as a delivery medium for instruction primarily for its ubiquity and insignificant costs. However, it is not chosen for its instructional effectiveness. Nor is it chosen as a medium particularly suited to carrying a range of information types for culturally diverse learners. In this context, creating systems for teaching and learning with the Web may well work to limit efficacy in learning, despite the Web's ever developing technical capacities to carry multimedia materials and information, and its growing provision for various levels of complexity in learner material interactions. While many learners might possess the basic information and navigational skills to contend with information access on the Web, instructional designers are yet to consider those aspects of this medium that determine its effectiveness for all learners, whatever their cultural characteristics.

Henderson has determined, as late as 1996, 'the relationship between cultural context and instructional design has received little attention in the educational technology and instructional design literature' (Henderson, 1996 85). It seems apparent that the lack of research to target cultural issues in instructional design for distributed and interactive learning systems, such as those being placed on the Web by Australian and overseas universities in ever increasing numbers, is even more noticeable and is likely to have serious consequences, particularly for students as well as for universities. Indeed, a recently published government funded report in the area of Internet use by Australian universities, makes a clear recommendation that 'the university sector should be proactive in profiling and accommodating characteristics of user need that will require compatible network technologies' (Bruce, $1996 \mathrm{xi}$ ).

This paper rationalises a methodology for research into the use of Web sites as pedagogic vehicles for flexible learning, especially for students of diverse cultural backgrounds. It describes an original conceptual framework for conducting such research-one that is presently guiding our own work in this area.

\section{FLEXIBLE LEARNING AND THE USE OF THE WEB}

The concept of flexible learning has evolved alongside developments in new technologies in four main phases. The initial phases are considered by Nguyen, et al (1996), Peacock (1995), and others, to have focused on, (i) correspondence and radio broadcasts (directed at isolated learners in farming and mining communities); (ii) video and television broadcasts, which allowed greater approximation of the 
traditional classroom experience; and, (iii) computer conferencing, electronic mail and voice mail, which supported greater levels of synchronous and asynchronous communication across distance and time. A fourth phase is set to emerge in the later 1990's and will be focused on direct student access to computer based remote databases, hypermedia and multimedia information and dial up access to video materials. In this fourth phase, students will be in control of the time, place and pace of study (Peacock, 1995), and will have direct access to an expanding and dynamic knowledge base and extensive communicative facilities. The Web is an emerging technology but already possesses the functionalities described in this fourth phase: the Web is placed to be the technology most likely to carry flexible learning into a new phase of development.

Of course, the move towards flexible learning for all students, on campus and distance, is being driven not only by technological imperatives but also by economic and pedagogical ones. There is a declining ratio of academic staff to students; and students are increasingly being encouraged to invest greater independence in, and control over, their learning. Indeed, over the last 20 years or so there have been significant changes in policies, organisation, staffing, funding and management of universities in Australia, usually as a result of government directives and policies (Chalmers and Fuller, 1996). One consequence of these changes is that students are now a much more diverse group, particularly in cultural characteristics, and are more likely to study in mixed modes that are suited to flexible learning.

\section{EDUCATIONAL POTENTIAL OF THE WEB}

The nature of the World Wide Web has attracted a great deal of rhetoric in favour of its potential to provide for a student centred model of learning, where the learner is both intrinsically motivated and active in the learning environment (Becker and Dwyer, 1994). At first glance there is much in the Web that appeals to educators, for example, the hypermedia information structures in the Web allow for the chunking of information, a feature that, in light of information processing theories of working memory, might be seen to support the cognitive processing of knowledge (Biggs and Moore, 1993). There have also been suggestions that in providing for browsing and thematic exploration, the Web facilitates higher order cognitive processes, such as transfer and knowledge application (Jacobson and Spiro, 1995; Oliver, Herrington, and Omari, 1996); whilst at a more conceptual level, there has always been a case made for hypertext mirroring the ways in which much of human thinking occurs, by association rather than linearly or procedurally (Burton, Moore, and Holmes, 1995; Bush, 1945; Minsky, 1975). Furthermore the Web, in terms of being a dynamic, extensive and extensible information base, provides for the ultimate in resource rich learning.

It is important to remember that the Web, as hypermedia or hypertext, is itself only a medium for conveying information data. Hypermedia does not possess a single or normative information structure, hypermedia documents are created to 
conform or fit to a structure, imposed by their instructional designers. At one extreme this structure might be highly ordered, supported by a constrained and sequential set of links. At another extreme, the hypermedia may be nonsequential and supported only by referential links. In many cases, a coherent hypermedia document, such as a Web site, might comprise a mix of these structures. It is, then, the nature and application of these structures that determines the effectiveness of engagement with the data carried in the Web in order for generative learning to occur. Furthermore, to maximise engagement, the information needs to conform to a structure that best fits or suits both the type of knowledge being conveyed as well as the learning preferences and requirements of diverse groups of learners.

However, there is no guidance, and virtually no empirical research, to help determine the most appropriate ways of using the Web to stimulate effective learning at tertiary level for all learners that are so targeted. It is apparent that instructional design for Web based learning systems cannot, and does not, exist outside a consideration of cultural influences-both the cultural influences operating on the authors and instructional designers of Web based learning materials, and similarly, those influences that impact on the interpretation of such materials by learners.

\section{THE INFLUENCE OF CULTURE}

Defining culture is a difficult proposition. Many different classifications exist in relation to national culture (Kluckhohn and Strondbeck, 1961; Roackeach, 1973; Hall, 1959, 1990; Hofstede, 1984; Hofstede and Bond, 1988). Supporters of the convergence theory claim that, due to influences such as technology and trends towards globalisation of information, societies will become more and more alike (Child, 1981; Negandhi, 1985); others who support the divergence theory believe that national differences are not divisible by such influences, and that such differences will operate to limit or negate the value of distributed information and learning systems aimed at multiple cultures (Hofstede 1984, Cheung and Burn, 1994; Nelson and Clark, 1994; Lewis, 1996). Perhaps the most pervasive view is that culture is a manifestation of ways in which an identifiable group adapts to its changing environment; that people belong to more than a single cultural group, embodying a subset rather than a totality of a culture's identifiable characteristics; and that they do not remain totally allegiant to their birth culture (Henderson, 1996; Scheel and Branch, 1993).

Whatever the theory, there appears to be consensus that culture has a definite and very strong influence on the design and use of information, communication and learning systems, as well as on their management, despite the lack of identifiable research in these areas. In all areas of human activity, the behaviour of people is affected by the values and attitudes that they hold and the societal norms which surround them. When values are widely shared by a group of people, they are provided with a common mechanism by which they can share understandings and interpretations of their world, and establish what is important and clarify priorities. 
As nations develop and organisations become more technologically advanced and globally oriented, their culture changes and this, in turn, has an effect on individuals' attitudes and values (Adler, 1991). Culture, however, is more than just an abstraction. It also consists of a distinctive symbol system together with artefacts, that capture and codify the important and common experiences of a group. Distinctive significant symbolic meanings and values develop around information, its use and structuring in any cultural group. Also, at a practical level, when the act of instructional design translates this information into products or artefacts of learning, that artefact embodies cultural influences, such as the instructional designer's world view, their values, ideologies, culture, class and gender, and, their commitment to a particular design paradigm (Henderson, 1996).

These interacting cultural factors have a particular importance for the diffusion and efficacy in use, of distributed learning systems, such as the Web, and the products and materials of learning provided in those systems.

\section{A MODEL FOR INVESTIGATION}

We presently have a situation where cultural influences in distributed information, communication and learning systems, especially those centred in the Web, are present and are identifiable, but are largely created unknowingly. As a result, such systems probably work to the detriment of large groups of culturally diverse learners who cannot identify with the instructional designs in Web-based systems of teaching and learning, originating as they do, in single cultural identities. Given the instructional agendas currently being set by universities for the present and future use of the Web, it is reasonable to suggest that there will be a mismatch between instructional intention and learning outcome. This mismatch will become more noticeable as Web based flexible learning systems are increasingly put into place in the later 1990s and into the new millennium.

Henderson describes three existing instructional design paradigms in static instructional multimedia: (i) culturally unidimensional or exclusionary; (ii) inclusive; and, (iii) inverted (Henderson, 1996). In the first paradigm, cultural minority groups go unrepresented. Scheel and Branch (1993) have attempted to describe the reasons for this, and in doing so explain various manifestations of what Rattansi (1992) has termed, deracialisation.. Deracialisation occurs when there is an unintentional or intentional exclusion or avoidance of, or insulation from, issues of appropriate cultural contextualisation in the production of multimedia learning materials. In the second paradigm, Henderson (1996) acknowledges the adoption of an inclusive or perspectives instructional design approach, where the instructional designer includes the social, cultural, economic and/or historical perspectives and/or contributions of minority groups. 'In this paradigm, instructional design is driven by social justice and equity issues, while instructional design solutions range from soft to hard multiculturalism' (Henderson, 1996 91), or what Scheel and Branch (1993) term 'mild to strong interventions' (p. 9). In a third paradigm, the instructional designer will attempt to 
approach the design task from the perspective of one or more minority cultures, that is, from an inverted curriculum or critical theory-postmodernist paradigm (Henderson, 1996 93).

Each of these instructional design paradigms has been determined by Henderson (1996), to be unsatisfactory in terms of providing culturally appropriate instruction in static (ie. CD-ROM) multimedia products. It is reasonable to hypothesise that these are the very paradigms that currently also dominate in distributed information, communication and learning systems, presently being provided on the Web by universities for teaching and learning for culturally diverse students.

\section{A RESEARCH METHODOLOGY}

The following research programme is promulgated to enable a triangulation of qualitative and quantitative data in order to assess the cultural contextualisation of learning with the Web as a distributed learning environment. It is envisaged that this research programme will commence in Australia in 1998.

In selecting a research methodology, we have been guided by both Howe and Eisenhart (1990) and Reeves (1993), who argue that any methodology employed should be judged in terms of its success in investigating educational problems deemed important. Moreover, Salomon (1991) describes the contrast between analytic research that is focused on isolating effective instructional treatments and systemic research focused on understanding how instructional treatments work in practice. This suggests that analytic and systemic approaches are complementary: 'the analytic approach capitalises on precision while the systemic approach capitalises on authenticity' (Salomon, 1991 16). Both analytic and systemic methods are being used in this research programme. Also, the nature of learning based on the Web, with its high degree of individualisation, 'meshes precisely with the naturalistic assumption of individual constructions of reality' (Neuman, 1989 48). Indeed, specific strategies based on case study methods are highlighted in our research program so we can elicit these individual constructions.

At all stages of the research programme, it is crucial that a mixture of strategies be used to collect and analyse data within methodologies that are based in narrative, case study, and survey approaches (Patton, 1990).

The aim of this three year research project is to identify the nature and improve the efficacy of models of flexible, open and distance learning created in the World Wide Web by universities. The following hypotheses will be tested:

- Existing cultural influences in instructional materials designed and delivered on the World Wide Web by Australian universities, and intended for use by culturally diverse students, are minimal and ineffective.

- The efficacy of learning based in the use of the World Wide Web for instructional purposes can be improved by the adoption of a culturally appropriate model of instructional design. 
- Culture is a significant factor in determining the effectiveness of learning materials created in the World Wide Web and intended for use by culturally diverse students.

In testing these hypotheses we intend to provide empirical research to help determine the most appropriate ways of using the Web to stimulate effective learning at tertiary level for all learners, whatever their cultural heritage or perspectives.

There are three phases in the research, corresponding to three temporal stages.

\section{Phase one-year one}

The major focus for this phase is to identify the existing instructional design paradigms that exist in distributed information, communication and learning systems provided by Australian universities for culturally diverse groups of learners, both internal and external to Australia. This will be accomplished in five stages:

1. Administering brief written survey questionnaires to Australian universities via email and/or post, with the intention of identifying those that provide for open, distance and/or flexible learning in courses that are studied in part or in whole, on the Web, using distributed communication, information and/or multimedia technologies.

2. From this database, randomly select Web course sites: (a) at underg aduate level, (b) with large to small enrolments, (c) across a number of disciplines, (d) from various large urban to small country universities, and (d) ranged across the Australian States and Territories.

3. Create data collection instruments to enabie identification of instructional design paradigms used in the distributed learning systems on the Web sites selected in (2). Identification will be based upon how well the Web sites conform to critical identifiers of the three existing instructional design paradigms identified by Henderson (1996) that are hypothesised to exist in Web based systems created for flexible learning.

Currently, we are hypothesising that the instruments will involve checklists that include the following sorts of relevant instructional design elements seen to belong to the three cultural paradigms: (a) the underlying pedagogic philosophy of each Web course site; (b) the Web course site's epistemology; (c) each site's instructional sequencing (for instance, is there a holist (horizontal hypertext) or partist (linear hypertext) layout to the interface design of what is usually seen as the content menu page/s?); (d) the degree of inbuilt individual versus collaborative strategies; (e) hypermedia navigation pathways that cater for individual learning styles (Carver, Howard and Levelle 1996) as well as novice, expert, and the progression from novice to expert, Web users; (f) the ratio of American, Canadian, British, Australian and New Zealand active internet links to non Anglo Western active internet links included within each Web course site; (g) word count of key concepts and examples of, for instance, a single 'truth' or multiple theoretical perspectives; (h) semantic 
chunking of text versus traditional paragraph structure; and (i) appropriate/inappropriate culturally contextualised graphics, animation, video clips, sound, and colours.

4. Undertake collection of data from the instruments devised in (iii) above. This will involve the following strategies to promote reliability amongst the researchers of their coding of the data. One Web course site will be selected; each researcher will use the data collection instrument/s to codify the site; their respective codification will be comparatively noted. Each researcher's codification will be tabulated and put through a reliability check devised by Marland, Patching and Putt (1992) and subsequently ratified by Henderson, et al. (in press). This reliability check will be administered randomly throughout the codification of all selected Web course sites. We would be expecting above an $80 \%$ agreement for validity. Where discrepancies occur in the codification, the researchers will negotiate an unanimous decision.

5. Report the findings of the first phase. These findings should stand alone as a significant contribution to the literature on the pedagogic design of Web distributed learning materials. As well, they will highlight the cultural contextualisation of such teaching learning materials. Additionally, the findings provide the conceptual entry point to the second major phase of the research program.

\section{Phase two-year two}

The major aim of this phase is to (a) create and implement a number of Web sites based on a fourth instructional design paradigm centred in a view of multiple cultures (Henderson, 1966) and (b) implement a pilot study to test the paradigm's effectiveness.

The primary endeavour of the multiple cultural model is to design a learning environment that promotes equity of outcomes for all learners. A major weakness in the multicultural, inclusive and inverted paradigms is avoidance of the cognitive, epistemological, and philosophical aspects of inter related cultural educational contexts. A multiple cultural model that has been used and researched since 1990 is offered as an alternative way to conceptualise the cultural contextualisation of instructional design in distributed learning environments (for a synthesis of some of the research corpus, see Henderson, Patching and Putt, 1996). The multiple cultural model strives for a coherent interplay between various implicit and explicit cultural logics: those of the academic, 'mainstream' and 'minority' cultures. First, instructional design in a multiple cultural model needs to overtly recognise the specific requirements of the 'mainstream' tertiary culture. These are expressed through the content to be taught, types of assessment, the written and oral genres, research methodologies, and culturally-specific ways of promoting cognitive development within an academic environment. Second, as academic culture is embedded in each society's dominant culture, aspects of the macro culture, particularly systemic factors, need to be included in the overall instructional design of any distributed learning environment. Third, it is also necessary that instructional design incorporate the cultures of the other identifiable groups of 
learners, that is, their knowledge and preferred ways of thinking and doing in a manner that goes beyond tokenism.

Thus, the multiple cultural model does not assume one instructional pedagogy as immutable but provides an epistemological and pedagogic pluralism in which multiple ways of constructing knowledge and understanding are valued, and it prompts learners to interrogate those pedagogies in the construction of their own knowledge. In this way cultural contextualisation is visible in the instructional design of the Web learning materials.

There are six stages in this second phase of the research plan.

1. Select a number of existing foundation units offered in the School of Management Information Systems at Edith Cowan University and in the School of Education at James Cook University. The criteria for selection are that students enrolled in these units will have culturally diverse backgrounds and be internally and externally enrolled.

2. Instructionally design a series of Web sites using these foundation units in accordance with the multiple cultures paradigm, and focussed on providing student learning for students of diverse cultural backgrounds. Because the multiple cultures paradigm is centred within Vygotsky's socio-cultural historical theory of learning, scaffolding strategies within the student's zone of proximal development are incorporated in the instructional design of the Web sites. Such scaffolding will target the various strategies of modelling, coaching, cognitive apprenticeship, etc., as proposinded in the theory of situated cognition (Choi and Hannafin, 1995). The strategies will necessarily be aimed at canvassing a range of cognitive and metacognitive thinking skills.

3. Program the series of Web sites, utilising the expertise of computer science postgraduate students. Programming will also incorporate tracking of student movement within the Web site. The tracking has dual purposes. Firstly, it will provide students with self determined and program determined access to appropriate scaffolding support that provides cognitive and navigational guidance from a 'more capable other' (which, in this case, is the scaffolding strategies instructionally designed within the Web sites). Secondly, the tracking will be utilised as research data to ascertain the where, how and when of students' intranet and, hopefully, internet movements within and outside the Web sites.

4. Undertake a pilot study of these Web sites at the Perth Institute of Business and Technology to test the veracity and appropriateness of (a) the instructional design in the Web sites and (b) the data collection instruments. This Institute and its foundation units typically attract students of diverse cultural and national groups, enrolled internally and externally, and who are representative of students studying these same or similar foundation units at Edith Cowan and James Cook University. Some students from diverse cultural groups will be invited to be involved in the trailing evaluation of the Web sites. Checklists, student diaries, observations, open ended questionnaires, data from the programmed tracking, interviews, and stimulated recall interviews will be used. 
The main function of the first four instruments is to obtain data about the multiple cultural contextualisation of the content and the instructional design features of the Web sites. Tracking data will provide evidence of its efficiency in actually doing what is intended, that is, providing cognitive scaffolding and navigational support to the learners and obtaining their 'what, where and when' navigational movements. Interviews based on the analysis of the tracking data should provide us with an understanding of why students took certain paths, options, and actions while studying with the Web materials. Interviews will also provide data about the students' perceptions of whether these strategies promoted their learning and were related to culturally identified ways of thinking and doing.

The last methodology, stimulated recall audiotaped interviews focussed on a replay of a split screen videotaped session of the students as they studied with the Web materials, is based in the mediating process paradigm (Shulman, 1986). The paradigm directs attention to student thought processes that mediate or come between instructional stimuli and learning outcomes. Analysis of the coded data allows the researchers to elicit the thinking and attitudinal processes actually engaged in whilst the students studied with the Web materials. The mediating process paradigm has been successfully tested in previous research with culturally diverse groups (Henderson and Patching, 1995; Henderson, Patching and Putt, 1996; Putt, Patching and Henderson, 1996).

5. Edit the Web sites based on analysis of the data collected in (4).

6. Commence initial visits to universities in Australia and other countries (based on previous enrolments of students studying externally to Edith Cowan and James Cook universities, it is predicted that these countries will include Malaysia, Taiwan, Thailand and Hong Kong), to identify likely subjects and organise qualitative and quantitative collection strategies, as preparation for Phase Three as described below.

\section{Phase three-year three}

This phase aims to investigate the degree of success in student learning that students of different cultural groups have as a result of using the Web based materials designed in the paradigm of multiple cultures. The students $(n>1500)$ chosen for investigation will include students enrolled both at Edith Cowan and James Cook Universities, students who are enrolled internally and externally to these universities, and who are therefore studying within and outside Australia. They will also include students who can be, collectively, identified with a range of representative cultural groups. The study will incorporate quantitative and qualitative data collection instruments, such as:

1. pre, post, and post delay content questionnaires;

2. pre and post attitudinal, anxiety, and usage questionnaires (King, Henderson and Putt, 1996), to be incorporated within the Web site pages;

3. a five category Likert questionnaire focussed upon the interface design features of the Web sites, to be incorporated within the Web site pages; 
4. case study of 12 ethnically diverse students; two from each Web unit site;

5. diary kept by each of these, and a random sample of other, students;

6. stimulated recall audiotaped interviews with these 12 students;

7. observations of the students identified in (4) and (5) at the various Australian and overseas study sites;

8. other evaluative open ended questionnaire interviews of the students identified in (4) and (5);

9. tracking data.

\section{CONCLUSION}

It is anticipated that various outcomes will be achieved which will add to the body of knowledge on flexible learning, instructional design, cultural influences in learning and teaching, and pedagogically effective culturally contextualised World Wide Web instructional materials. Such outcomes include an empirically researched evaluation of (a) the impact of teaching and learning based on the Web for culturally diverse tertiary students; (b) an instructional design model which can be applied to develop culturally appropriate teaching and learning on the Web; and (c) flexible learning materials provided by Australian universities on the Web in terms of their cultural sensitivities.

\section{REFERENCES}

Adler, N. J. (1991) International dimensions of organisational behaviour (Second ed.). PWS-Kent, Boston.

Alexander, S. (1995) Teaching and learning on the World Wide Web. Paper presented at AusWeb95: The First Australian World Wide Web Conference, Southern Cross University, New South Wales, 30 April-2 May, 1995.

Becker, D., and Dwyer, M. (1994) Using hypermedia to provide learner control. Journal of Educational Multimedia and Hypermedia, 3(2), 155-172.

Biggs, J. B., and Moore, P. J. (1993) The process of learning (Third ed.). Prentice Hall, Sydney.

Bruce, H. W. (1996) Internet, AARNet and academic work: A longitudinal study, Department of Employment, Education, Training and Youth Affairs (DEETYA), Canberra. November, 1996.

Burton, J. K., Moore, M., and Holmes, G. A. (1995) Hypermedia concepts and research: An overview. Computers in Human Behaviour, 11(3-4), 345-369.

Bush, V. (1945) As we may think. The Atlantic Monthly, 176(1), 101-108.

Carver, C., Howard, R., and Levelle, E. (1996) Enhancing student learning by incorporating learning styles into adaptive hypermedia, in Interactive multimedia and hypermedia (eds. P. Carlson and F. Makedon) (pp. 118-123). Association for the Advancement of Computers in Education, Charlottesville, VA. 
Chalmers, D., and Fuller, R. (1996) Teaching for learning at university . Kogan Page, London.

Cheung, H. K., and Burn, J. M. (1994) Distributing global information systems resources in multinational companies: A contingency model. Journal of Global Information Management, 2(3), 14-27.

Child, J. (1981) Culture, contingency and capitalism in the cross-national study of organizations, in Research in organizational behavior (eds. L. L. Cummings and B. M. Staw ),(pp. 303-356). JAI Press, Greenwich, CT.

Choi, J., and Hannafin, M. (1995) Situated cognition and learning environments: Roles, structures and implications for design. Educational Technology Research and Development, 43(2), 53-69.

Harasim, L. (1995). The virtual university: New approaches to higher education in the 21 st century. Paper presented at ASCILITE95. The 12th Annual Conference of the Australian Society for Computers in Learning in Tertiary Education, Melbourne, 3-7 December, 1995.

Henderson, L. (1996) Instructional design of interactive multimedia: A cultural critique. Educational Technology Research and Development, 44(4), 86-104.

Henderson, M., and Patching, W. (1995). Multimedia interactivity: Relating cognitive processing and click and drag activities. Educational Multimedia and Hypermedia, 1995, Association for the Advancement of Computing in Education, Charlottesville, VA. 318-323.

Henderson, L., Patching, W., and Putt, I. (1996) Off-campus preservice teacher education via interactive multimedia technology: An indigenous cohort case study, in Interactive multimedia and hypermedia (eds. P. Carlson and F. Makedon), (pp. 300-305), Association for the Advancement of Computers in Education, Charlottesville, VA.

Henderson, L., Patching, W., and Putt, I. (in press) Non-indigenous students thinking: Studying with interactive multimedia courseware designed for indigenous students.

Henderson, L., Putt, I., Ainge, D., and Coombs, G. (in press) Comparison of students' thinking processes when studying with WWW, IMM, and text-based materials.

Hofstede, G. (1984) Culture's consequences . Sage, Beverly Hills, CA.

Howe, K., and Eisenhart, M. (1990) Standards for qualitative (and quantitative) research: A prolegomenon. Educational Researcher, 19(4), 2-9.

Jacobson, M., and Spiro, R. (1995) Hypertext learning environments, cognitive flexibility and the transfer of complex knowledge. Journal of Educational Computing Research, 12(4), 301-333.

Kluckhohn, F., and Strodtbeck, F. (1961) Variations in value orientations . Row Peterson, Evanston, IL.

Lewis, R. D. (1996). When cultures collide: Managing successfully across cultures . Nicholas Brealey Publishing Ltd.

Marland, P.W., Patching W.G. and Putt, I. J. (1992) Learning from Text: Glimpses inside the minds of distance learners. James Cook University, Townsville. 
Minsky, M. (1975) A framework for representing knowledge, in The psychology of computer vision (ed. P. H. Winston), McGraw Hill, New York.

Nelson, K. G., and Clark, T. D. (1994) Cross-cultural issues in Information Systems research: A research program. Journal of Global Information Management, 2(4), 19-29.

Neuman, D. (1989) Naturalistic inquiry and computer-based instruction: Rationale, procedures and potential. Educational Technology Research and Development, 37(3), 39-51.

Nguyen, A. T. A., Tan, W., \& Kezunovic, L. (1996). Interactive multimedia on the World Wide Web: Implementation and implications for the tertiary education sector. In R. Debreceny \& A. Ellis (Eds.), Proceedings of AusWeb96: The Second Australian World Wide Web Conference. (Also available at, http://www.scu.edu.au/ausweb96/), (pp. 551-557). Gold Coast, Australia: Southern Cross University.

Oliver, R. (1996) Interactions in multimedia learning materials: The things that matter in Proceedings of Third Interactive Multimedia Symposium, The learning superhighway: New world, new worries? (eds. C. McBeath and R. Atkinson), (pp. 303-308), Promaco Conventions Ltd, Perth, Western Australia.

Oliver, R., Herrington, J., \& Omari, A. (1996). Creating effective instructional materials for the World Wide Web. In R. Debreceny \& A. Ellis (Eds.), Proceedings of AusWeb96: The Second Australian World Wide Web Conference. Also available at, http://www.scu.edu.au/ausweb96/, (pp. 485491). Gold Coast, Australia: Southern Cross University.

Paulsen, M. F. (1992) Computer mediated communications and distance education around the world. From Bulletin Boards to Electronic Universities, 7, 31-37.

Peacock, K. A. (1995) Distance education in a univesrity setting: connectirg to the global classroom. Available, http://www.utirc.utoronto.ca/Distance Ed/distedreport.html [on-line]. University of Toronto, Canada, October, 1995.

Pelton, J. N. (1996) Cyberlearning versus the university. The Futurist, NovemberDecember, 1996, 17-20.

Putt, I., Patching, W., and Henderson, L. (1996) Teachers' Thinking Elicited from Interactive Multimedia Professional Development Courseware. Educational Technology Research and Development 44(4), 7-22.

Rattansi, A. (1992) Changing the subject? Racism, culture and education in Race, culture and difference (eds. J. Donald and A. Rattansi),(pp. 11-48). Sage, London.

Reeves, T. (1993) Pseudoscience in computer based instruction: the case of learner control research. Journal of Computer Based Instruction, 20(2), 39-46.

Reeves, T. (1996) A model of the effective dimensions of interactive learning on the world wide web, in Interactive multimedia and hypermedia (eds. P. Carlson and F. Makedon), AACE Charlottesville, VA.

Rokeach, M. (1973) The nature of human values . Free Press, New York.

Rossman, P. (1992) The emerging worldwide electronic university: Information age global higher education. Greenwood Press, Westport. 
Rudra, A. (1994) AARNet and ERNET: An era for fostering international academic research, in Proceedings of International networking: Education, training and change (ed. N. F. Ellerton), (pp. 104-109), Edith Cowan University, Perth, Western Australia.

Salomon, G. (1991) Transcending the qualitative-quantitative debate: The analytic and systemic approaches to educational research. Educational Researcher, 20(6), 10-18.

Scheel, N., and Branch, R. (1993) The role of conversation and culture in the systematic design of instruction. Educational Technology, 3(3), 5-14.

Shulman, L. S. (1986) Paradigms and research programs in the study of teaching: A contemporary perspective, in Handbook of research on teaching (ed. M. C. Wittrock), (pp. 3-36), Macmillan, New York.

Wild, M. (1996a) Designing appropriate learning environments in instructional multimedia: The role of theory. Paper presented at Higher Education Research and Development Society of Australasia (HERDSA) Annual Conference: Different approaches-Theory and practice in Higher Education, Perth, Western Australia, 8-12 July 1996.

Wild, M. (1996b) Invited Presentation: The future of flexible learning and the use of technologies in tertiary education. Open Learning Seminar, University of Technology, Sydney. 15 July, 1996.

Wild, M., and Omari, A. (1996) Developing educational content for the Web: Issues and ideas, in Proceedings of AusWeb96: The second Australian World Wide Web Conference. (Also available at, http://www.scu.edu.au/ausweb96/), (eds. R. Debreceny and A. Ellis), (pp. 353-355), Southern Cross University Gold Coast, Australia.

\section{BIOGRAPHIES}

Martyn Wild teaches in the School of Management Information Systems, Edith Cowan University, Western Australia. He has published in diverse fields of information technology research, including, IT use in teacher education; interactive multimedia and learning; instructional design in on-line and multimedia environments; interface design; and human-computer interaction. He is currently developing performance support systems for teaching and learning.

Lyn Henderson is senior lecturer at James Cook University, in North Queensland, Australia. Her fields of research interests concern the cultural contextualisation of instructional design in multimedia and the World Wide Web, mental models, thinking processes and teaching-learning strategies used by teachers and learners when interacting with electronic databases, interactive multimedia and the World Wide Web. 